\title{
Cardiopulmonary
}

Support

and Physiology

\section{Tumor necrosis factor- $\alpha$ production in whole blood after cardiopulmonary bypass: Downregulation caused by circulating cytokine-inhibitory activities}

\author{
J. Börgermann, MD ${ }^{\mathrm{a}, \mathrm{c}}$ \\ I. Friedrich, $\mathrm{MD}^{\mathrm{a}}$ \\ S. Flohé, $M D^{c}$ \\ J. Spillner, $M D^{\mathrm{a}, \mathrm{c}}$ \\ M. Majetschak, MD \\ 0 . Kuss ${ }^{\mathrm{b}}$ \\ A. Sablotzki, MD \\ T. Feldt, $M D^{c}$ \\ J. C. Reidemeister, $M^{C}$ \\ F. U. Schade, $\mathrm{PhD}^{\mathrm{c}}$
}

From the Department of Cardiac and Thoracic Surgery a and the Institute of Medical Epidemiology, Biometrics, and Informatics, ${ }^{\text {b }}$ Martin-Luther-University Halle-Wittenberg, Halle/Saale, and the Department of Surgery, Clinical Research Group Shock \& MOF, ${ }^{\mathrm{c}}$ University Hospital of Essen, Essen, Germany.

Supported by grants from the Deutsche Forschungsgemeinschaft (Schm 74/ 13-2), IFORES University of Essen (J.B.), and Fonds der Chemischen Industrie (F.U.S.).

Received for publication April 28, 2001; revisions requested June 22, 2001; revisions received Nov 28, 2001; accepted for publication Dec 12, 2001.

Address for reprints: Jochen Börgermann, MD, Martin-Luther-University Halle-Wittenberg, Department of Cardiac and Thoracic Surgery, Ernst-Grube-Str 40, 06120 Halle/Saale, Germany (E-mail: Jochen.Boergermann@t-online.de).

J Thorac Cardiovasc Surg 2002;124:608-17

Copyright (C) 2002 by The American Association for Thoracic Surgery

0022-5223/2002 $\$ 35.00+0 \quad \mathbf{1 2 / 1 / 1 2 2 3 0 0}$

doi:10.1067/mtc.2002.122300
Objectives: Cardiopulmonary bypass is associated with the release of proinflammatory cytokines (tumor necrosis factor $\alpha$, interleukin $1 \beta$, interleukin 6 , and interleukin 8) and anti-inflammatory cytokines (interleukin 10 and transforming growth factor $\beta_{1}$ ). On the one hand this cytokine release is related to the postoperative systemic inflammatory response syndrome, and on the other hand it is related to deterioration of the immune system, for example in monocyte or polymorphonuclear neutrophil function, leading to an increased susceptibility to infections. To gain further insight into the alterations of immune cell reactivity and possible regulatory mechanisms, we studied lipopolysaccharide-induced tumor necrosis factor $\alpha$ synthesis in whole blood from cardiac surgical patients.

Methods: Fifteen patients undergoing elective heart surgery with cardiopulmonary bypass were included in the study. Ex vivo lipopolysaccharide-induced tumor necrosis factor $\alpha$ synthesis was measured in a whole blood assay before, during, and after bypass. Corresponding tumor necrosis factor $\alpha$ messenger RNA levels were determined by semiquantitative reverse transcriptase-polymerase chain reaction. In addition, the influence of patient serum on whole blood responsiveness and its relationship to anti-inflammatory cytokines were evaluated in vitro.

Results: Tumor necrosis factor $\alpha$ synthesis was significantly reduced after 30 minutes of cardiopulmonary bypass and showed the lowest values at the end of bypass (mean \pm SD $0.109 \pm 0.105 \mathrm{ng} / 10^{6}$ white blood cells after 30 minutes of bypass and $0.050 \pm 0.065 \mathrm{ng} / 10^{6}$ white blood cells at the end of bypass, vs $0.450 \pm$ $0.159 \mathrm{ng} / 10^{6}$ white blood cells preoperatively, $\left.P<.001\right)$. As a further indication of reduced cytokine biosynthesis, diminished messenger RNA levels for tumor necrosis factor $\alpha$ were detected. Serum withdrawn from patients at the end of cardiopulmonary bypass reduced tumor necrosis factor $\alpha$ synthesis in heterologous blood from healthy volunteers highly significantly to $39.93 \% \pm 23.18 \%$ relative to control serum $(P=.005)$ and preoperatively drawn serum $(P=.024)$. This effect was dose 
dependent and was not specific for lipopolysaccharide-induced tumor necrosis factor $\alpha$ synthesis. Anesthesia and heparin administration did not influence tumor necrosis factor $\alpha$ production significantly. Ex vivo tumor necrosis factor $\alpha$ synthesis was negatively related to interleukin 10 serum levels, positively but weakly related to interleukin 4 , and was not related to transforming growth factor $\beta_{1}$ (Spearman correlation coefficients $-0.565, P<.001,0.362, P<.001$, and $-0.062, P=.460$, respectively). However, interleukin 10 levels in patient serum after cardiopulmonary bypass were 300 -fold below the quantities needed for half-maximal inhibition of tumor necrosis factor $\alpha$ synthesis in vitro. Moreover, the inhibitory activity could not be removed by immune absorption of interleukin 10 .

Conclusions: These results suggest that during cardiac operations cytokine-inhibitory serum activities are released or newly formed. These activities could not be explained by the actions of interleukins 4 and 10 or transforming growth factor $\beta_{1}$. Although their exact nature remains undetermined, these substances may contribute to the diminished immune cell functions after cardiopulmonary bypass and thus need further characterization.

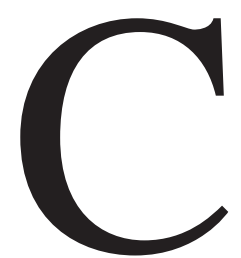

ardiac surgery, in particular with cardiopulmonary bypass (CPB), is associated with a wide variety of adverse physiologic and immunologic effects. Surgical trauma, ischemia-reperfusion, endotoxemia, and activation of monocytes by artificial surfaces are the predominant mechanisms that trigger the postoperative systemic inflammatory response syndrome. ${ }^{1,2}$ Key cells in the inflammatory processes, such as systemic inflammatory response syndrome and sepsis, are polymorphonuclear neutrophils. When activated, these cells release various inflammatory mediators, such as eicosanoids, proteolytic enzymes, oxygen radicals, and cytokines. Polymorphonuclear neutrophil reactivity is modulated by diverse cytokines. It has been shown that proinflammatory and anti-inflammatory cytokines are released during $\mathrm{CPB} .^{3-7}$ Whereas proinflammatory cytokines (such as tumor necrosis factor [TNF] $\alpha$, interleukin [IL] $1 \beta$, IL-6, and IL-8) alter myocardial contractility, peripheral circulation, and other organ functions, ${ }^{8,9}$ anti-inflammatory cytokines (such as IL-4, IL-10, and transforming growth factor $\beta_{1}$ [TGF- $\left.\beta_{1}\right]$ ) may play a role in the deterioration of the immune system after CPB. ${ }^{10,11}$ On the other hand, anti-inflammatory cytokines are believed to limit complications induced by an overshooting proinflammatory reaction. It is therefore believed that the balance of proinflammatory and anti-inflammatory mediators is of crucial importance for an adequate host reaction to insults associated with systemic inflammatory response syndrome. Under conditions of polytrauma and sepsis, dysregulation of in vitro cytokine synthesis by isolated monocytes or whole blood has been shown to be associated with the clinical outcome or the extent of trau- ma. ${ }^{12,13}$ To our knowledge only a few studies have investigated cytokine synthesis in the blood compartment in patients undergoing CPB. ${ }^{14}$ This study was therefore designed to evaluate cytokine synthesis and its regulatory mechanisms in whole blood after CPB. The whole blood system was chosen rather than isolated peripheral blood mononuclear cells to minimize artifacts arising from cell isolation or the lack of cells and humoral factors involved in the peripheral blood mononuclear cell response in their natural environment. ${ }^{15}$

\section{Patients and Methods \\ Patients}

After approval by the ethics committee of our faculty, 15 patients scheduled to undergo elective cardiac surgery with CPB were enrolled in this prospective study. Patients with autoimmune diseases, those with hepatic or renal dysfunction, and patients receiving steroids or nonsteroidal anti-inflammatory drugs were excluded. All patients provided written, informed consent. In all cases the outcome was uneventful. Biometric, clinical, and perioperative data of the 15 patients are summarized in Table 1.

\section{Anesthesia and CPB Technique}

Aspirin was stopped 7 days before the scheduled date of surgery, and antianginal substances were continued until the day of operation. Premedication consisted of flunitrazepam $(25-30 \mu \mathrm{g} / \mathrm{kg}$ body weight orally) for night sedation, with another dose 2 hours before induction of anesthesia. Perioperatively, the following parameters were monitored: electrocardiogram, central venous pressure, pulmonary artery pressure, and arterial pressure. Body temperature was monitored continuously. Anesthesia was induced with etomidate (0.2-0.4 mg/kg body weight), sufentanil (2-4 $\mu \mathrm{g} / \mathrm{kg}$ body weight), and pancuronium bromide $(0.1 \mathrm{mg} / \mathrm{kg}$ body weight $)$. Patients were endotracheally intubated and mechanically venti- 
TABLE 1. Biometric, clinical, and perioperative data $(\mathbf{n}=$ 15)

\begin{tabular}{lc}
\hline Sex ratio (male/female) & $8: 7$ \\
Age (y, mean \pm SD) & $64.53 \pm 9.21$ \\
New York Heart Association functional & $2.47 \pm 0.64$ \\
$\quad$ classification (mean \pm SD) & \\
Procedure & 11 \\
$\quad$ Coronary artery bypass grafting & 2 \\
$\quad$ Aortic valve replacement & 2 \\
$\quad$ Coronary artery bypass grafting plus aortic & \\
$\quad$ valve repalcement & $207.87 \pm 57.06$ \\
Operative time (min, mean \pm SD) & $97.07 \pm 44.18$ \\
CPB time (min, mean \pm SD) & $58.80 \pm 26.90$ \\
Crossclamp time (min, mean \pm SD) & $34.94 \pm 0.67$ \\
Central temperature ( ${ }^{\circ} \mathrm{C}$, mean \pm SD) & $30.93 \pm 24.71$ \\
Intensive care unit stay (h, mean \pm SD) & $14.14 \pm 5.23$ \\
Intubation time (h, mean \pm SD) & $552.31 \pm 347.83$ \\
Blood loss over chest drain (mL, mean \pm SD) & $2.14 \pm 1.46$ \\
Transfused packed red blood cells (units, & \\
$\quad$ mean \pm SD) & \\
\hline
\end{tabular}

lated with oxygen and air (inspired oxygen fraction 0.5) to maintain a $\mathrm{PaCO}_{2}$ of 35 to $40 \mathrm{~mm} \mathrm{Hg}$ or an end-tidal carbon dioxide level of $4.5 \%$ to $5.0 \%$. Balanced anesthesia was maintained with sufentanil and isoflurane $(0.5 \%-1.0 \%$ volume percentage).

The CPB technique was standardized with a roller pump (Stöckert Instrumente $\mathrm{GmbH}$, Munich, Germany), a flat sheet membrane blood oxygenator (COBE CML Duo; COBE Cardiovascular, Heimstetten, Germany) and identical priming solution for all patients. Cardioplegia was induced by antegrade application of cooled Bretschneider solution (Custodiol; Dr F. Köhler Chemie, Alsbach-Hähnlein, Germany) into the aortic root. Nonpulsatile blood flow during $\mathrm{CPB}$ was $2.5 \mathrm{~L} /\left(\mathrm{min} \cdot \mathrm{m}^{2}\right.$ body surface area), and conditions were mildly hypothermic $\left(35^{\circ} \mathrm{C}\right)$. The administration of heparin for cannulation and antagonization with protamine sulfate were performed in a standardized fashion. After the operation, pharmacologic support was instituted according to hemodynamic requirements.

\section{Blood Sampling}

Blood was withdrawn at 11 time points from the central venous line and collected in plastic tubes (ammonium heparin $[9 \mathrm{~mL}]$ and serum [9 mL]; Sarsted Monovette; Nümbrecht, Germany). After sampling, whole blood was immediately prepared for ex vivo endotoxin stimulation. Serum samples were allowed to clot, centrifuged (3.500 rpm for 10 minutes), and the separated serum was frozen at $-80^{\circ} \mathrm{C}$ until assay. Time points of blood sampling were as follows: T1, 8:00 AM, day of operation, before anesthesia; T2, after induction of anesthesia; T3, after administration of heparin; T4, 30 minutes after start of CPB; T5, 5 minutes after unclamping of the aorta; T6, at the end of CPB; T7, 4 hours after CPB; T8, first postoperative day, 8:00 AM; T9, second postoperative day, 8:00 AM; T10, fourth postoperative day, 8:00 AM; and T11, sixth postoperative day, 8:00 AM.

\section{Ex Vivo Endotoxin Stimulation of Whole Blood}

Whole blood was mixed 1:1 (volume/volume) with cell culture medium (RPMI 1640; Gibco-BRL, Eggenstein, Germany) contain- ing 64-IU/mL penicillin, $64-\mu \mathrm{g} / \mathrm{mL}$ streptomycin, and $20-\mathrm{mmol} / \mathrm{L}$ sodium hydrogen carbonate). Mixtures were set up in flat-bottomed 24-well plates (Falcon 3072 Microtest III tissue culture tube; Becton Dickinson, Heidelberg, Germany) in a total volume of $800 \mu \mathrm{L}$. Samples were prepared in triplicate. Cultures were incubated with $(100 \mathrm{ng} / \mathrm{mL})$ and without endotoxin (lipopolysaccharide from Salmonella friedenau, kindly provided by Dr Brade, Forschungszentrum Borstel, Borstel, Germany) for 4 hours at $37^{\circ} \mathrm{C}$ in a $5 \%$ carbon dioxide, water-saturated atmosphere. Supernatants were collected after centrifugation and stored at $-80^{\circ} \mathrm{C}$ until cytokine determination. The cell pellets were lysed with 0.05 mol/L guanidinium thiocyanate buffer for RNA isolation.

Total and differential white blood cell (WBC) counts were obtained for each blood sample with a Coulter counter (Coulter, Krefeld, Germany).

\section{Bioassay for TNF- $\alpha$-Inhibitory Capacity}

Heterologous whole blood from healthy volunteers was incubated with endotoxin $(10 \mathrm{ng} / \mathrm{mL})$ in the presence of additional patient serum withdrawn before the operation with $\mathrm{CPB}$, after the operation, and on the sixth postoperative day, as described previously. An equal amount of autologous donor serum served as control. The reduction in endotoxin-stimulated TNF- $\alpha$ secretion reflected the inhibitory capacity of the serum. The inhibitory capacity is expressed as percentage of the TNF- $\alpha$ production in whole blood cultures incubated in the presence of autologous donors serum.

\section{Enzyme-Linked Immunosorbent Assays}

Levels of cytokines in the supernatants of whole blood cultures and patient serum were measured with specific enzyme-linked immunosorbent assays (ELISAs). TNF- $\alpha$ concentration was determined with a monoclonal antihuman TNF- $\alpha$ antibody (Genzyme, Munich, Germany), a polyclonal antihuman TNF- $\alpha$ antiserum raised in rabbits, and a horseradish peroxidase-conjugated goat antirabbit immunoglobulin G serum (Dianova, Hamburg, Germany) as a detection system. For standards, recombinant human TNF- $\alpha$ (Genzyme) was used. All samples and standards were assayed in triplicate. Mean values for each were used in calculating sample concentrations through a linear regression analysis of the optical density (micro-ELISA autoreader Dynatech MR 5000 [Acterna Corporation, Deukendorf, Germany], test filter $405 \mathrm{~nm}$, reference filter $490 \mathrm{~nm}$ ) versus the TNF- $\alpha$ concentration on the standard curve. For the standard of each plate, $r^{2}$ was greater than 0.95 . The lower detection limit for the TNF- $\alpha$ ELISA was 30 $\mathrm{pg} / \mathrm{mL}$. Results of measurements in the supernatants of whole blood cultures were additionally normalized to represent nanograms per $10^{6} \mathrm{WBCs}$.

Serum levels of IL-4, IL-10, and TGF- $\beta_{1}$ were determined with commercially available ELISA kits according to the manufacturer guidelines (IL-4 and IL-10 from Biomedia, Baesweiler, Germany; TGF- $\beta_{1}$ from Genzyme). Acidification of serum samples for measurements of total TGF- $\beta_{1}$ was performed according to the manufacturer instructions. All samples and standards were assayed in duplicate. No adjustment was made for hemodilution. Lower detection limits were $1.5 \mathrm{pg} / \mathrm{mL}$ for IL-4, $3 \mathrm{pg} / \mathrm{mL}$ for IL-10, and 50 $\mathrm{pg} / \mathrm{mL}$ for TGF- $\beta_{1}$. 
TABLE 2. Primer sequences, cDNA amounts, and cycle numbers

\begin{tabular}{|c|c|c|c|}
\hline Primer & Sequence & cDNA $(\mu \mathrm{L})$ & Cycles \\
\hline \multicolumn{4}{|l|}{$\beta$-Actin } \\
\hline Sense & 5'-TGAAGTCTGACGTGGACATC-3' & $0.125-1.0$ & $25 ; 27$ \\
\hline Antisense & 5'-ACTCGTCATACTCCTGCTTG-3' & & \\
\hline \multicolumn{4}{|l|}{ TNF- $\alpha$} \\
\hline Sense & 5'-CAGAGGGAAGAGTTCCCCAG-3' & $0.25-2.0$ & $35 ; 37$ \\
\hline Antisense & 5'-CCTTGGTCTGGTAGGAGACG-3' & & \\
\hline
\end{tabular}

Primers were exon-intron overspanning or included an intron to rule out contamination of chromosomal DNA.

\section{Bioassay of TNF}

TNF bioactivity was determined in a cytolytic cell assay in the mouse fibrosarcoma cell line WEHI 164, clone 13 (gift of Dr Espevik, Institute of Cancer Research, University of Trondheim, Norway), as described previously. ${ }^{16}$ In brief, WEHI cells $(2 \times$ $10^{4}$ cells/well) were incubated with serial dilutions of supernatants in microtiter plates. After 18 hours, 10\% 3-(4,5-dimethylthiazol2-yl)-2,5-diphenyltetrazolium-bromide (MTT $5 \mathrm{mg} / \mathrm{mL}$ in phosphate-buffered saline solution; Sigma Deisenhofen, Germany) was added. The reaction was stopped after 4 hours by addition of 5\% formic acid in isopropanol (Merck, Darmstadt, Germany), and the content of reduced MTT was read in a micro-ELISA autoreader (MR 5000, test filter $570 \mathrm{~nm}$, reference filter $660 \mathrm{~nm}$; Dynatech). The titer of TNF, which is expressed in units per milliliter, was chosen as the reciprocal of the dilution necessary to cause $50 \%$ cell lysis. ${ }^{16}$ The specificity of this bioassay was tested by adding an antiserum against TNF- $\alpha$ (Genzyme) to the supernatants. It was found to neutralize more than $90 \%$ of the cytolytic activity measured with the WEHI assay.

\section{Immune Absorption of IL-10}

Aliquots of $300 \mu \mathrm{L}$ of patient serum were mixed 1:1 (volume/ volume) with medium (RPMI; Gibco-BRL) and incubated overnight at $4^{\circ} \mathrm{C}$ with $35 \mu \mathrm{L}$ protein G-Sepharose (Pharmacia, Freiburg, Germany) already swollen in phosphate-buffered saline solution and $50 \mu \mathrm{L}$ of antihuman IL-10 antibody (Biozol GmbH, Eching, Germany), antihuman HLA-DR antibody (isotype control; Becton Dickinson, Heidelberg, Germany), or phosphate-buffered saline solution. After centrifugation, supernatants were tested in the bioassay for TNF- $\alpha$-inhibitory capacity and the IL-10 ELISA.

\section{RNA Isolation, Complementary DNA Synthesis, and} Semiquantitative Reverse Transcriptase-Polymerase Chain Reaction

Total RNA was isolated from cell pellets of the endotoxin-stimulated whole blood by acid guanidinium thiocyanate-phenol-chloroform extraction and further by a commercial RNA preparation kit (RNeasy Total RNA Kit; QIAGEN, Düsseldorf, Germany) according to the manufacturer instructions. The amount and the purity of RNA were quantified by measuring the optical density at 260 and $280 \mathrm{~nm}$ with a Beckmann spectrophotometer (Pharmacia, Cambridge, United Kingdom). Approximately $1 \mu \mathrm{g}$ of total RNA was reverse transcribed with Moloney murine leukemia virus reverse transcriptase (Superscript; Gibco-BRL), 25 pmol oligodeoxythymidine primer, $0.1-\mathrm{mol} / \mathrm{L}$ dithiothreitol, and $10-\mu \mathrm{mol} / \mathrm{L}$ each nucleoside triphosphate (Perkin-Elmer, Weiterstadt, Germany) in a total volume of $20 \mu \mathrm{L}$. For further processing, the complementary DNA (cDNA) was diluted 1:5 with deionized water and stored at $-80^{\circ} \mathrm{C}$.

Polymerase chain reaction (PCR) was carried out as reported in detail elsewhere. ${ }^{17}$ In brief, PCR was performed with different amounts of cDNA, 200 pmol of each primer (Eurogentec, Köln, Germany), $0.2 \mu \mathrm{mol}$ deoxynucleoside triphosphate, and 1 unit Taq DNA polymerase (Roche Diagnostics GmbH, Mannheim, Germany) in a total volume of $100 \mu \mathrm{L}$. Reaction mixtures were placed in a thermocycler (Gene Amp PCR System 2400; Perkin-Elmer, Weiterstadt, Germany), and each PCR cycle consisted of the following: denaturation (30 seconds at $95^{\circ} \mathrm{C}$ ), primer annealing (30 seconds at $50^{\circ} \mathrm{C}$ for $\beta$-actin and at $56^{\circ} \mathrm{C}$ for TNF), and DNA extension (45 seconds at $72^{\circ} \mathrm{C}$ ). Primer sequences, cDNA amounts, and cycle numbers are shown in Table 2. PCR for each product was performed separately at four cDNA concentrations and a minimum of cycles to yield an amplificate, so that the amounts of the amplificates reflect the quantities of the cDNA and messenger RNA (mRNA) present in the preparation. Amplificates were quantified after separation on a $1.5 \%$ agarose gel with ethidium bromide fluorescence analysis (Fluorimager; Molecular Dynamics, Krefeld, Germany). PCRs were accepted as quantitative if fluorescence intensities of amplificates after linear regression versus cDNA dilutions resulted in a linear relationship $(r \geq$ 0.95). All measured PCR products were calculated on the amount of $1 \mu \mathrm{L}$ cDNA and normalized to the amount $\beta$-actin in each sample.

\section{Statistical Analysis}

Results are presented as mean \pm SD. For statistical analysis we used nonparametric methods (signed rank test, Wilcoxon test, nonparametric analysis of variance, Spearman correlation coefficient) whenever possible. All analyses if necessary accounted for the fact that measurements were repeatedly taken from the same patients. Pairwise comparisons analyses were Bonferroni adjusted to avoid spurious significances. Calculations were performed with SAS version 8e statistical software (SAS Institute, Inc, Cary, NC).

\section{Results}

\section{Ex Vivo TNF- $\alpha$ Synthesis in Whole Blood}

Lipopolysaccharide-induced TNF- $\alpha$ release of isolated whole blood obtained from patients before the operation 


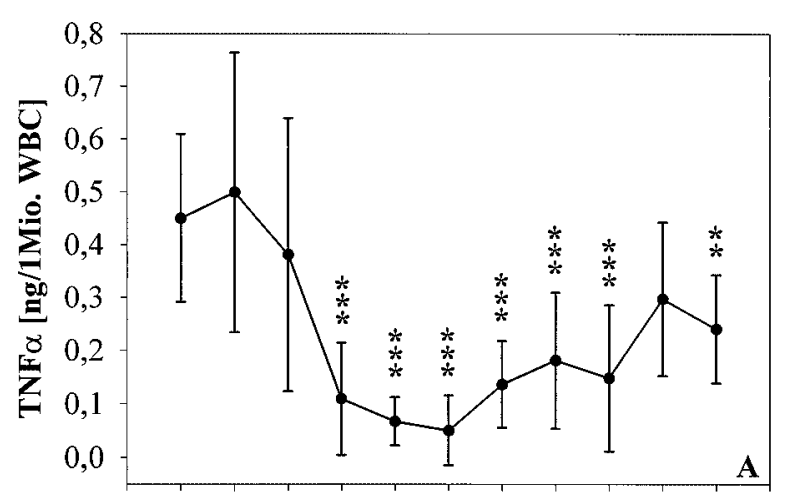

$\begin{array}{llllllllll}\mathrm{T} 1 & \mathrm{~T} 2 & \mathrm{~T} 3 & \mathrm{~T} 4 & \mathrm{~T} 5 & \mathrm{~T} 6 & \mathrm{~T} 7 & \mathrm{~T} 8 & \mathrm{~T} 9 & \mathrm{~T} 10 \mathrm{~T} 11\end{array}$

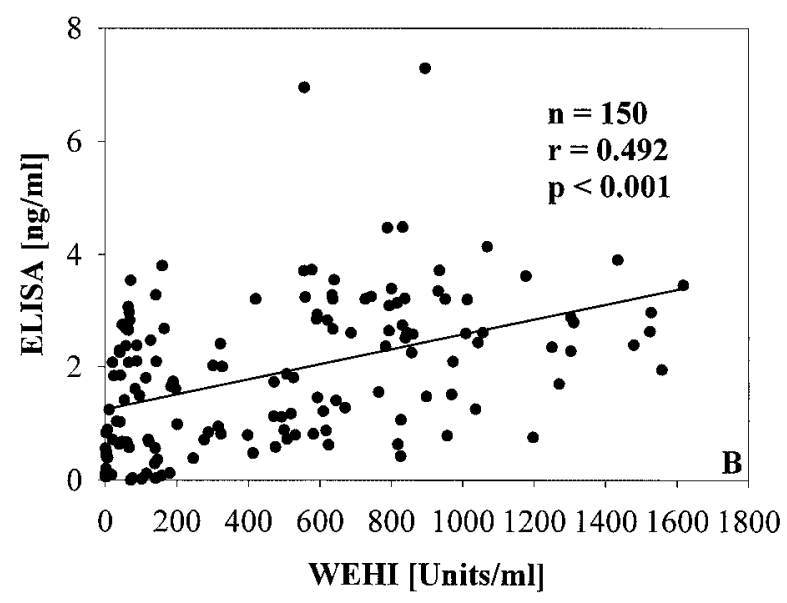

Figure 1. A, Ex vivo TNF- $\alpha$ synthesis of endotoxin-stimulated ( $S$ friedenau, $100 \mathrm{ng} / \mathrm{mL}$ ) whole blood normalized to $1 \times 10^{6}$ WBCs. Double asterisk indicates $\boldsymbol{P}<.01$ versus preoperative values (T1); triple asterisk indicates $P<.001 ; P$ values are Bonferroni adjusted and calculated as pairwise comparisons within a repeated measurement nonparametric analysis of variance model. Data points represent mean for $\mathbf{1 5}$ patients from triplicate cultures for each time point for each patient; error bars represent SD. B, Comparison between WEHI bioassay and enzyme-linked immunosorbent assay ( $\mathrm{n}=150$ ). High correlation between bioactive TNF and total TNF- $\alpha$ (line) indicates little interference by plasma proteins such as soluble TNF receptors (Spearman correlation coefficient $r=0.492, P<.001$ ).

with $\mathrm{CPB}$, during the operation, and at serial time points until the sixth postoperative day was studied. After stimulation with endotoxin $(100 \mathrm{ng} / \mathrm{mL})$, release of TNF- $\alpha$ could be observed in all patients at all time points (Figure 1, A). Because activated monocytes as well as granulocytes and lymphocytes represent potential sources of cytokines, and to exclude artifacts arising from hemodilution or intraoperative blood loss during $\mathrm{CPB}$, TNF- $\alpha$ production was normal- ized to white blood cell counts. Ex vivo TNF- $\alpha$ synthesis was significantly reduced after 30 minutes of $\mathrm{CPB}$ and showed the lowest value at the end of $\mathrm{CPB}$ (mean $\pm \mathrm{SD}$ $0.109 \pm 0.105 \mathrm{ng} / 10^{6} \mathrm{WBC}$ after 30 minutes of CPB [T4] and $0.050 \pm 0.065 \mathrm{ng} / 10^{6} \mathrm{WBC}$ at the end of CPB [T6] vs $0.450 \pm 0.159 \mathrm{ng} / 10^{6}$ WBC before operation [T1], $P<$ $.001)$. When TNF- $\alpha$ bioactivity measured by WEHI assay was compared with total TNF- $\alpha$ determined by ELISA, a highly significant correlation was found (Figure 1, B). The capacity of whole blood to synthesize TNF- $\alpha$ increased within the next days 3- to 5-fold, but it did not recover completely within the observation period. Whereas IL-6 and IL-8 serum levels were found to be increased after CPB in a way comparable to other studies (peak values at the end of CPB of $430 \mathrm{pg} / \mathrm{mL}$ and $89 \mathrm{pg} / \mathrm{mL}$, respectively), ${ }^{18}$ no significant TNF- $\alpha$ release was observed in unstimulated blood or serum at any of the 11 sampling points.

\section{TNF- $\alpha$ Messenger RNA Expression in} Lipopolysaccharide-Stimulated Whole Blood To gain further insight into the regulation of TNF- $\alpha$ synthesis after CPB, mRNA expression in lipopolysaccharidestimulated $(100 \mathrm{ng} / \mathrm{mL})$ whole blood was studied by reverse transcriptase-PCR in 6 cases. As shown in Figure 2, a significant suppression of mRNA expression for TNF- $\alpha$ was found after CPB (mean \pm SD $21.15 \% \pm 20.51 \%$, range $7.56 \%-29.55 \%$ ) of preoperative TNF- $\alpha$ mRNA expression, $P<.001)$. In parallel with the protein concentrations determined in the supernatants of ex vivo stimulated whole blood cultures, mRNA expression increased after operation to approximately $50 \%$ of preoperative values. Similar kinetics of lipopolysaccharide-stimulated cytokine release and mRNA expression support the hypothesis that the observed phenomenon is mediated by regulation at a transcriptional or pretranscriptional step of cytokine synthesis.

\section{TNF- $\alpha$-Inhibitory Activity in Patient Serum After CPB}

To test the hypothesis that the impaired ex vivo synthesis of TNF- $\alpha$ is caused by inhibitory substances circulating in patient serum after CPB, whole blood obtained from healthy volunteers was incubated with lipopolysaccharide in the presence of additional patient serum withdrawn before the operation, at the end of CPB, and on the sixth postoperative day. Autologous donor serum served as control. As shown in Figure 3, the addition of patient serum withdrawn at the end of $\mathrm{CPB}$ resulted in a highly significant reduction of TNF- $\alpha$ secretion to $39.93 \% \pm 23.18 \%$ (mean \pm SD) relative to control serum $(P=.005)$ and to preoperative serum $(P=.024)$. Increasing amounts of patient serum withdrawn after CPB resulted in a dose-dependent inhibition of lipopolysaccharide-stimulated TNF- $\alpha$ synthesis, whereas serum withdrawn before the operation and autologous donor serum had no marked effect. This finding excludes the possibility 

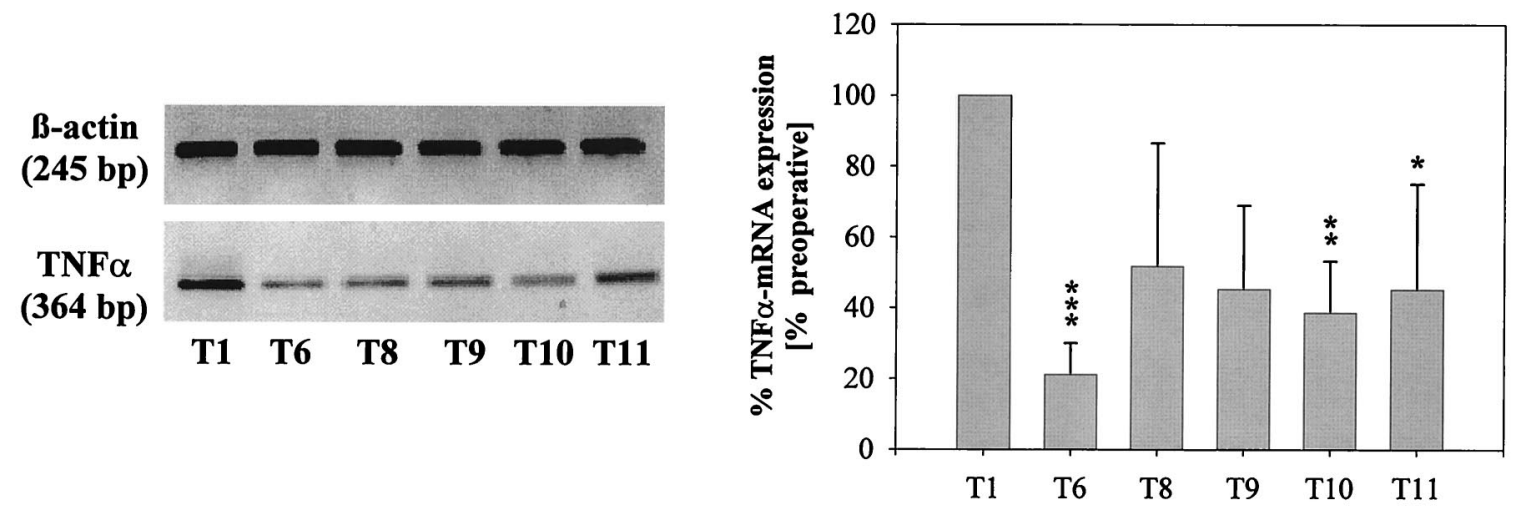

Figure 2. Analysis of TNF- $\alpha$ and $\beta$-actin mRNA in whole blood after 4 hours of stimulation by endotoxin ( $S$. friedenau, $100 \mathrm{ng} / \mathrm{mL}$ ). Left, Agarose gel stained with ethidium bromide of 1 typical patient among 6. Right, Results of semiquantitative reverse transcriptase-PCR. In parallel with protein secretion, expression of TNF- $\alpha$ mRNA was significantly reduced after CPB to $21.15 \% \pm 20.51 \%$ (range $7.56 \%-29.55 \%$ ) of preoperative values and had recovered to approximately $50 \%$ on postoperative day 6 . Bar heights represent mean for 6 patients; error bars represent SD. Asterisk indicates $P<.05$ versus preoperative values (T1); double asterisk indicates $P<.01$; triple asterisk indicates $\boldsymbol{P}<.001 ; \boldsymbol{P}$ values are Bonferroni adjusted and calculated as pairwise comparisons within a repeated measurement nonparametric analysis of variance model.

that a deficiency in serum components after CPB (eg, lipopolysaccharide-binding protein) contributes to the inhibited lipopolysaccharide response (Figure 4). Furthermore, when whole blood was activated with heat-killed streptococci or zymosan, TNF- $\alpha$ production was inhibited to the same degree by serum taken after CPB (data not shown). It therefore seems unlikely that substances that interfere with lipopolysaccharide (eg, soluble CD14 or bactericidal permeability-increasing protein) contribute to the inhibitory activity in patient serum. A highly significant correlation (Spearman correlation coefficient $r=0.492, P<.001)$ between TNF- $\alpha$ bioactivity measured by WEHI assay and TNF- $\alpha$ determined by ELISA indicates no relevant interference by TNF- $\alpha$-binding proteins (Figure $1, B$ ). In addition, when serum containing the inhibitory activity was added to volunteer whole blood after incubation with lipopolysaccharide, this did not diminish TNF- $\alpha$ as determined by either ELISA or WEHI assay. These results suggest that the inhibitory activity is neither due to substances interfering with lipopolysaccharide nor to substances interfering with the bioactivity of TNF- $\alpha$.

Influence of Heparin on TNF- $\alpha$ Synthesis In Vitro To investigate whether the suppression of cytokine synthesis during CPB is related to heparinization, the effects of increasing doses of heparin were studied in whole blood in vitro. Whole blood from healthy volunteers was incubated with lipopolysaccharide in the presence or absence of heparin (0.16-100 U/mL) for 4 hours. It was found that heparin in doses that exceeded the doses necessary for anticoagulation

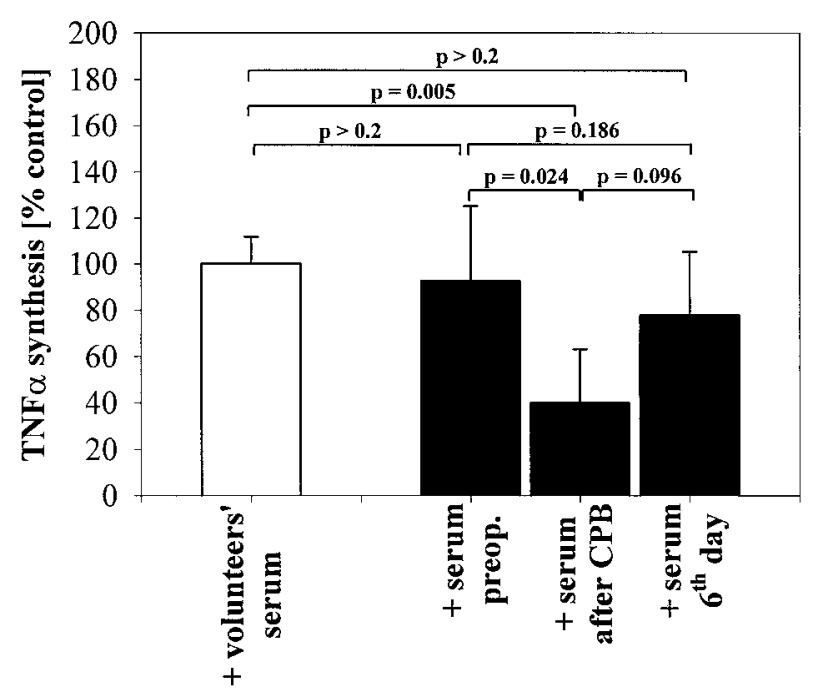

Figure 3. Inhibition of whole blood TNF- $\alpha$ synthesis by patient serum prepared after CPB. Mixtures contained $100 \mu \mathrm{L}(33 \%)$ additional serum and were stimulated with endotoxin $(S$. friedenau, $10 \mathrm{ng} / \mathrm{mL}$ ). Serum withdrawn at end of CPB caused statistically significant inhibition of TNF- $\alpha$ synthesis in heterologous whole blood from healthy volunteers relative to preoperative serum (preop.) or volunteer serum (control). Bar heights represent mean for 10 independent experiments; error bars represent SD. $P$ values were calculated by signed rank test if data from same patient were compared and by Wilcoxon test for comparison with control. All $\boldsymbol{P}$ values were Bonferroni adjusted.

during CPB by 10 times did not affect TNF- $\alpha$ synthesis in vitro (Figure 5). This suggests that heparin is not responsible for decreased TNF- $\alpha$ production during and after CPB. 


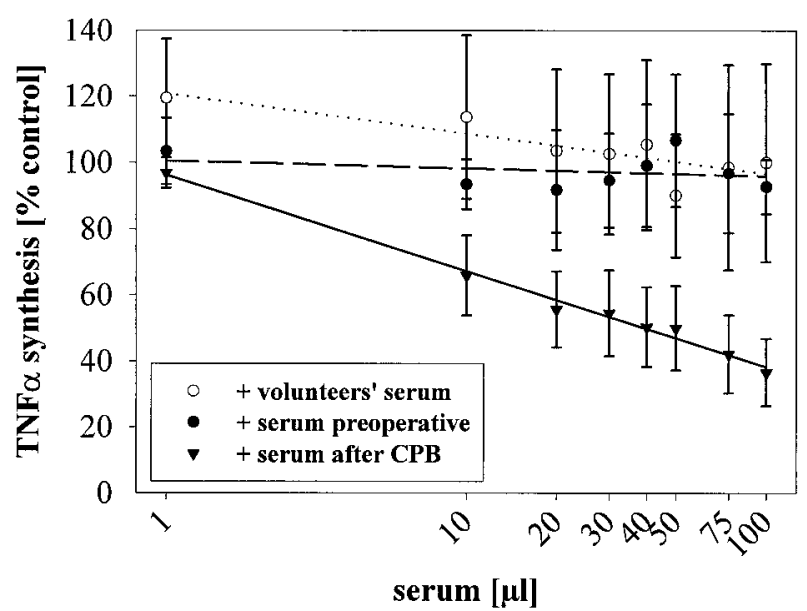

Figure 4. Dose-dependent inhibition of whole blood TNF- $\alpha$ synthesis by patient serum prepared after CPB. Heterologous whole blood from healthy volunteers was incubated with endotoxin ( $S$. friedenau, $10 \mathrm{ng} / \mathrm{mL}$ ) for 4 hours in presence of 1 to $100 \mu \mathrm{L}$ $(0.33 \%-33 \%)$ patient serum taken before operation or at end of CPB and volunteer serum. Control indicates TNF- $\alpha$ synthesis on endotoxin stimulation in presence of $100 \mu \mathrm{L}$ volunteer serum. For serum taken after CPB, linear regression analysis revealed significant decline of $12.55 \%$ (95\% confidence interval $11.30-13.82$, $\boldsymbol{P}<.0001$ ) for every unit of concentration of patient serum on $\log$ scale. Serum withdrawn before operation $(b=0.97,95 \%$ confidence interval -2.55 to $4.50, P=.523)$ or control serum $(b=5.25$, 95\% confidence interval $1.98-8.52, P=.0077$ ) had no or negligible influence on TNF- $\alpha$ synthesis. Data points represent mean; error bars represent SD.

Relationship Between TNF- $\alpha$ Production and Antiinflammatory Cytokines in Patient Serum

It has been shown that IL-4, IL-10, and TGF- $\beta_{1}$ are potent inhibitors of TNF- $\alpha$ synthesis both in vivo and in vitro. Therefore, the spontaneous releases of these cytokines at the indicated time points were measured (Table 3).

Mean $( \pm$ SD) IL-4 levels dropped from $106.90 \pm 63.15$ $\mathrm{pg} / \mathrm{mL}$ before the operation to $9.78 \pm 10.48 \mathrm{pg} / \mathrm{mL}$ after the administration of heparin $(P<.001)$ and remained at this very low level until the end of CPB. After the operation the IL-4 serum concentrations increased continuously, and they reached preoperative baseline values on the sixth postoperative day.

IL-10 was barely detectable until a rapid release after unclamping of the aorta, and it peaked at the end of CPB $(241 \pm 192 \mathrm{pg} / \mathrm{mL}$ after unclamping [T5] and $318 \pm 186$ $\mathrm{pg} / \mathrm{mL}$ end of CPB [T6], vs $36 \pm 71 \mathrm{pg} / \mathrm{mL}$ before operation [T1], $P<.001)$. Within the next 48 hours, IL-10 progressively declined to preoperative values.

TGF- $\beta_{1}$ was detectable in all patients at all time points, with a preoperative baseline value of $17.16 \pm 12.30 \mathrm{ng} / \mathrm{mL}$. At the end of CPB, TGF- $\beta_{1}$ concentrations increased insig-

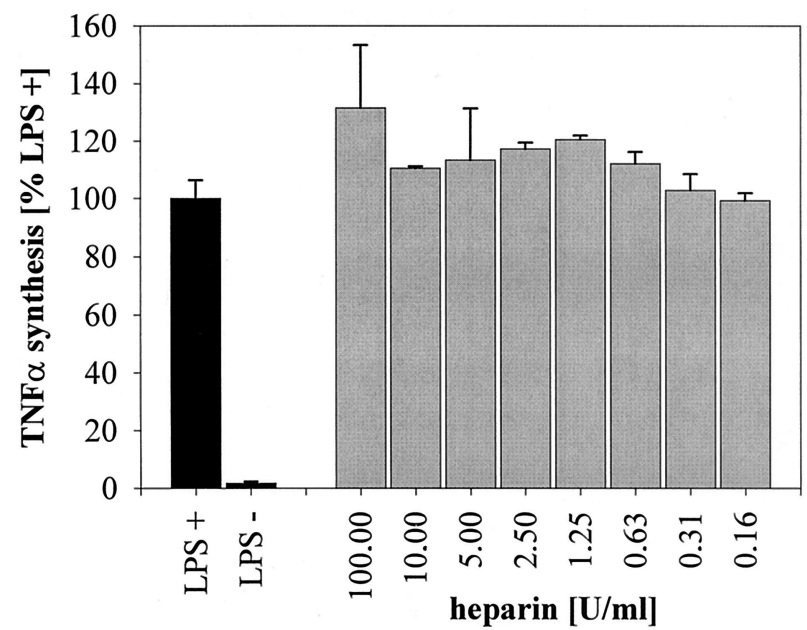

Figure 5. No inhibition of TNF- $\alpha$ synthesis by heparin. Whole blood was incubated with endotoxin $(10 \mathrm{ng} / \mathrm{mL}, S$. friedenau; LPS) for 4 hours in absence or presence of heparin $(0.16-100 \mathrm{U} / \mathrm{mL})$. Doses that exceeded those used for CPB by 10 times did not affect TNF- $\alpha$ production in vitro. Bar heights represent mean for 4 independent experiments; error bars represent SD.

nificantly to $22.59 \pm 13.15 \mathrm{ng} / \mathrm{mL}$. Afterward there was a decrease to $8.53 \pm 8.35 \mathrm{ng} / \mathrm{mL}$ on the first postoperative day, and the concentrations remained at this level during the remainder of the observation period.

Spearman correlation analysis between ex vivo lipopolysaccharide-induced TNF- $\alpha$ synthesis and anti-inflammatory cytokines in patient serum showed that IL-10 was negatively correlated with TNF- $\alpha$ production in whole blood $(r=-0.565, P<.001)$, whereas IL-4 showed a weak positive correlation $(r=0.362, P<.001)$ and TGF- $\beta_{1}$ was not related $(r=-0.062, P=.460)$. However, in vitro studies revealed that the concentrations of recombinant human IL-10 needed to cause half-maximal inhibition of TNF- $\alpha$ synthesis in human blood were about 300 times higher than those found in patient serum after CPB (data not shown). In addition, as shown in Figure 6, after immune absorption of IL-10, the inhibitory potential of serum withdrawn at the end of CPB was not altered.

\section{Discussion}

This study was carried out to investigate whole blood responsiveness to endotoxin stimulation as an indicator of leukocyte function and its regulatory mechanism after CPB. It has been well documented that CPB leads both to a proinflammatory response ${ }^{1,3,8}$ and to diminished humoral and cell-mediated immunity. ${ }^{4,19}$ The resulting attenuation of immune functions may pave the way for infectious or septic complications, which primarily contribute to increased morbidity and mortality after major surgery, especially cardiac surgery. We found a substantially diminished capacity of ex 
TABLE 3. Correlation of TNF- $\alpha$ synthesis and circulating anti-inflammatory cytokines ( $n=15)$

\begin{tabular}{|c|c|c|c|c|}
\hline & TNF- $\alpha$ (ng/10 6 WBC) & IL-4 (pg/mL) & IL-10 (pg/mL) & TGF- $\beta_{1}(\mathrm{ng} / \mathrm{mL})$ \\
\hline T1 & $0.450 \pm 0.159$ & $106.90 \pm 63.15$ & $36 \pm 71$ & $17.16 \pm 12.30$ \\
\hline $\mathrm{T} 2$ & $0.499 \pm 0.265$ & $121.98 \pm 76.04$ & $40 \pm 82$ & $18.18 \pm 14.66$ \\
\hline T3 & $0.381 \pm 0.258$ & $9.78 \pm 10.48^{*}$ & $34 \pm 102$ & $18.99 \pm 15.54$ \\
\hline T4 & $0.109 \pm 0.105^{*}$ & $10.30 \pm 8.83^{*}$ & $29 \pm 37$ & $14.27 \pm 10.67$ \\
\hline T5 & $0.067 \pm 0.045^{*}$ & $11.74 \pm 9.47^{*}$ & $241 \pm 192^{*}$ & $17.44 \pm 12.74$ \\
\hline T6 & $0.050 \pm 0.065^{*}$ & $25.97 \pm 37.59 \dagger$ & $318 \pm 186^{*}$ & $22.59 \pm 13.15$ \\
\hline T7 & $0.136 \pm 0.081^{*}$ & $48.59 \pm 27.12 \ddagger$ & $121 \pm 100^{*}$ & $16.20 \pm 13.49$ \\
\hline T8 & $0.181 \pm 0.128^{*}$ & $60.38 \pm 68.86 \ddagger$ & $88 \pm 73^{*}$ & $8.53 \pm 8.35$ \\
\hline T9 & $0.148 \pm 0.137^{*}$ & $36.03 \pm 40.50^{*}$ & $77 \pm 107$ & $9.09 \pm 10.55$ \\
\hline T10 & $0.297 \pm 0.145$ & $78.17 \pm 72.28$ & $41 \pm 74$ & $10.93 \pm 12.79$ \\
\hline T11 & $0.240 \pm 0.102 \dagger$ & $123.57 \pm 103.24$ & $50 \pm 67^{*}$ & $11.60 \pm 9.57$ \\
\hline$r$ & & 0.362 & -0.565 & -0.062 \\
\hline$P$ value & & $<.001$ & $<.001$ & .460 \\
\hline
\end{tabular}

Values are mean \pm SD. $P$ values are Bonferroni adjusted and calculated as pairwise comparisons within a repeated measures nonparametric analysis of variance model. Spearman correlation coefficient $(r)$ was calculated versus ex vivo TNF- $\alpha$ synthesis.

${ }^{*} P<.001$ versus preoperative values (T1).

$\dagger P<.01$ versus preoperative values (T1).

$\ddagger P<.05$ versus preoperative values (T1).

vivo lipopolysaccharide-stimulated whole blood to synthesize TNF- $\alpha$ as early as 30 minutes after CPB. This is in agreement with a report describing reduced IL-2, interferon $\gamma$, and TNF- $\alpha$ production from peripheral blood mononuclear cells after CPB. ${ }^{14}$ Because white blood cell counts increase during $\mathrm{CPB}$, hemodilution or loss of cells synthesizing TNF- $\alpha$ is not responsible for the observed phenomenon. Moreover, when TNF- $\alpha$ synthesis was normalized to the white blood cell counts, the effect was even more pronounced. Because TNF- $\alpha$ production was not affected after induction of anesthesia, it seems unlikely that drugs used for anesthesia interfere with the ability of leukocytes to synthesize cytokines, as has been assumed by others. ${ }^{20}$ The finding that the expression of mRNA transcripts for TNF- $\alpha$ showed the same kinetics as the protein release supports the hypothesis that the synthesis of TNF- $\alpha$ is inhibited at a point either preceding transcription or at the transcriptional level. These results appear to contradict previous studies. Hattler and coworkers ${ }^{21}$ reported enhanced TNF- $\alpha$ mRNA-expression in isolated peripheral blood mononuclear cells in 3 of 6 patients after CPB. However, corresponding to the diminished protein secretion, all our 6 patients investigated had markedly reduced TNF- $\alpha$ mRNA expression in lipopolysaccharide-activated whole blood after CPB (range 7.56\%$29.55 \%$ of preoperative values). Similar results (ie, reduced proinflammatory cytokine expression in whole blood or monocytes) have been observed under conditions of polytrauma and sepsis. ${ }^{12,13}$ A major reason for these discrepancies may be that we used whole blood from our patients, whereas in other studies isolated mononuclear cells were studied. The latter technique necessarily included the removal of serum components, such as circulating inhibitors. Although we did not detect TNF- $\alpha$ in unstimulated blood or

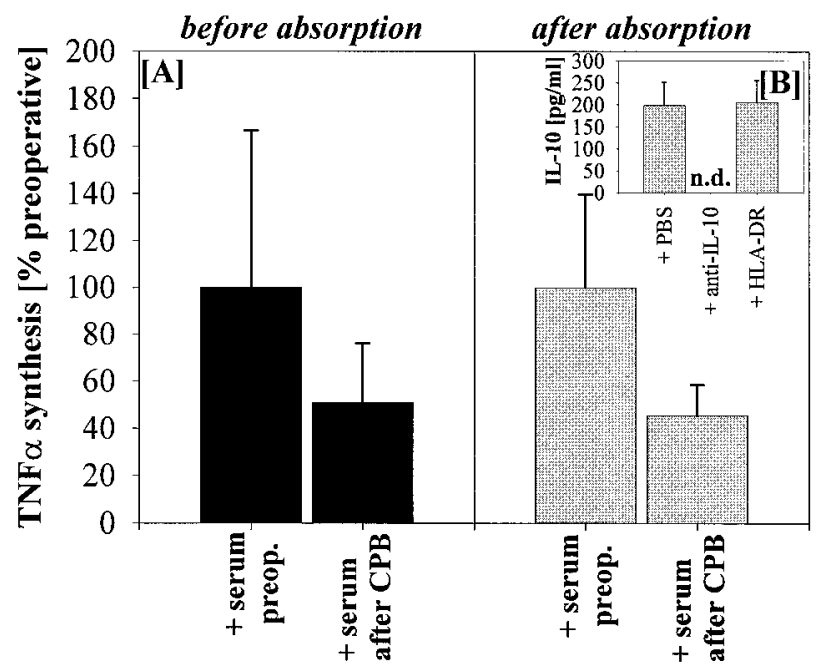

Figure 6. Immune absorption of interleukin-10 does not remove inhibitory activity from patient serum. A, Inhibitory activity in patient serum after CPB before immune absorption is shown on left. When IL-10 was completely removed by immune absorption (right), serum after CPB still contained potent inhibitory activity $(P=.075$ vs preoperative serum). $B$, Result of immune absorption with anti-IL-10 antibodies, HLA-DR antibodies (isotype control), or phosphate-buffered saline solution (PBS, control); n.d., not detectable. Bar heights represent mean for 3 independent experiments; error bars represent SD.

serum, some authors have measured low amounts of circulating TNF- $\alpha .{ }^{6}$ This discrepancy between reduced synthesis in whole blood and the presence of TNF- $\alpha$ in serum from patients after CPB may indicate that other macrophages or endothelial or myocardial cells are the source of the sys- 
temic cytokinemia. Wan and colleagues ${ }^{22}$ pointed out that major quantities of proinflammatory cytokines may originate from the heart after reperfusion of the ischemic myocardium. These findings are also supported by previous observation of a significant correlation between TNF- $\alpha$, IL-6, and IL-8 levels and the ischemic time in patients undergoing coronary artery bypass grafting or cardiac transplantation. ${ }^{8,18}$

The endotoxin hyporesponsiveness of whole blood after CPB could have been related to the mechanical stress exerted on blood cells by foreign surfaces (shear forces) as well as to the release of immunosuppressive mediators during or after cardiac surgery. To test the possibility that circulating anti-inflammatory mediators control the responsiveness of blood cells during and after $\mathrm{CPB}$, patient serum was tested with regard to influence on TNF- $\alpha$ synthesis in a heterologous whole blood system. We found that patient serum obtained after CPB contained potent TNF- $\alpha$-inhibitory activity. This serum activity did not interfere with endotoxin or the bioactivity of TNF- $\alpha$. The latter finding excludes the possibility that soluble TNF receptors released after $\mathrm{CPB}^{6}$ contribute to the inhibitory activity. These results and the substantial suppression of TNF- $\alpha$ mRNA transcripts strongly support the idea that the inhibitory activity is targeted at cytokine synthesis and does not interfere with the released protein.

Recently considerable interest has focused on the release of anti-inflammatory cytokines after CPB, such as IL-4, IL-10, and TGF- $\beta_{1}$. The involvement of these cytokines in the endotoxin desensitization of polymorphonuclear neutrophils after cardiac surgery can be assumed, because they all profoundly suppress proinflammatory cytokine synthesis in vivo and in vitro. ${ }^{10,11,23-25} \mathrm{In}$ accord with the data from other groups, we found a significant release of IL-10 after declamping 7,26 and slightly elevated TGF- $\beta_{1}$ serum levels after CPB. ${ }^{4}$ In contrast with previous studies, ${ }^{5}$ we were able to detect IL-4 in the serum of patients after CPB. Spearman correlation analysis revealed that IL-4 was positively but weakly correlated with lipopolysaccharide-induced TNF- $\alpha$ synthesis ex vivo, and IL-10 was negatively correlated. However, in vitro experiments demonstrated that IL-10 peak-levels in patient serum after CPB were 300 -fold below quantities of recombinant human IL-10 needed for halfmaximal TNF- $\alpha$ inhibition in vitro. Furthermore, immune absorption of IL-10 did not alter the inhibitory potential of patient serum. On the basis of these results, IL-10 can be ruled out as the main humoral factor responsible for impaired leukocyte function after cardiac surgery. IL-4 took a course reverse to that of the TNF- $\alpha$-inhibitory activity in patient serum. TGF- $\beta_{1}$ serum concentrations were not correlated with TNF- $\alpha$ production. It therefore seems unlikely that any of these mediators contributed largely to the total inhibitory activity in patient serum after cardiac surgery.
Some drugs commonly used in cardiac operations may influence cytokine production and release. In vitro studies showed that cytokine gene expression in human lipopolysaccharide-stimulated and interferon $\gamma$-stimulated mononuclear cells is inhibited by heparin. ${ }^{27}$ We therefore tested the influence of heparin on TNF- $\alpha$ synthesis in whole blood. Heparin in doses 10-fold higher than those necessary for anticoagulation during CPB did not inhibit TNF- $\alpha$ synthesis in vitro. Aprotinin, a serine protease inhibitor, partially inhibits cleavage and secretion of the membrane-bound precursor form of soluble TNF- $\alpha .{ }^{28}$ However, in recently published studies neither the use of heparin-coated circuits nor the administration of a high-dose regimen of aprotinin prevented or significantly attenuated cytokine release and neutrophil activation. ${ }^{29}$ In addition, preoperative administration of steroids has been shown to abolish cytokine release in heart surgery. ${ }^{30}$ Yet the patients in our examination received neither steroids nor nonsteroidal anti-inflammatory drugs.

A widely known in vitro and in vivo phenomenon of endotoxin hyporesponsiveness, termed endotoxin tolerance, is characterized by diminished synthesis of cytokines caused by a previous contact of monocytes and macrophages with low amounts of lipopolysaccharide. ${ }^{31}$ Endotoxemia as a result of bacterial translocation from the gut has been described during CPB. ${ }^{32}$ Endotoxin tolerance could therefore be a reason for the diminished TNF- $\alpha$ synthesis after CPB. Although endotoxin tolerance and the trauma caused by CPB both result in diminished cytokine production, the underlying mechanisms are still obscure. It should therefore be emphasized that endotoxin tolerance differs in various aspects from the phenomenon observed here. Usually, the development of endotoxin tolerance in humans requires more time ( $>3$ hours) than under CPB (30 minutes). ${ }^{31}$ Impaired cytokine synthesis in patients after CPB is accompanied by a markedly reduced HLA-DR expression on monocytes, ${ }^{33}$ leading to an immunodeficient state, whereas after induction of endotoxin tolerance no changes of HLA-DR expression on monocytes occur, and the resistance to bacterial and viral infections is enhanced. It therefore seems that a reduced capacity to synthesize cytokines must not necessarily be congruent with endotoxin tolerance.

In summary, cardiac operations involving CPB lead to a diminished lipopolysaccharide-induced TNF- $\alpha$ synthesis in the blood compartment. This hyporesponsiveness seems at least in part to be controlled by currently unknown circulating inhibitory activities. Because cytokines such as TNF- $\alpha$ are important molecules for the integrity of the host immune response (eg, antigen presentation), this may contribute to postoperative immunosuppression and to the increased susceptibility to infectious complications. Further characterization of the involved mediators and in particular their regulation is necessary to gain a better understanding 
of the underlying pathogenesis and to develop therapeutic strategies.

We thank Meike Rolfing for her excellent technical assistance. We are grateful to the staff of the operating room and the intensive care unit of the department of Thoracic and Cardiovascular Surgery for support in sample collection.

\section{References}

1. Wan S, LeClerc JL, Vincent JL. Cytokine responses to cardiopulmonary bypass: lessons learned from cardiac transplantation. Ann Thorac Surg. 1997;63:269-76.

2. Kirklin JK, Westaby S, Blackstone EH, Kirklin JW, Chenoweth DE, Pacifico AD. Complement and the damaging effects of cardiopulmonary bypass. J Thorac Cardiovasc Surg. 1983;86:845-57.

3. Kawamura T, Wakusawa R, Okada K, Inada S. Elevation of cytokines during open heart surgery with cardiopulmonary bypass: participation of interleukin 8 and 6 in reperfusion injury. Can J Anaesth. 1993;40: 1016-21.

4. Sablotzki A, Dehne M, Welters I, Menges T, Lehmann N, Gorlach G, et al. Alterations of the cytokine network in patients undergoing cardiopulmonary bypass. Perfusion. 1997;12:393-403.

5. Steinberg JB, Kapelanski DP, Olson JD, Weiler JM. Cytokine and complement levels in patients undergoing cardiopulmonary bypass. J Thorac Cardiovasc Surg. 1993;106:1008-16.

6. McBride WT, Armstrong MA, Crockard AD, McMurray TJ, Rea JM. Cytokine balance and immunosuppressive changes at cardiac surgery: contrasting response between patients and isolated CPB circuits. $\mathrm{Br} \mathrm{J}$ Anaesth. 1995;75:724-33.

7. Seghaye M, Duchateau J, Bruniaux J, Demontoux S, Bosson C, Serraf $\mathrm{A}$, et al. Interleukin-10 release related to cardiopulmonary bypass in infants undergoing cardiac operations. J Thorac Cardiovasc Surg. 1996;111:545-53.

8. Hennein HA, Ebba H, Rodriguez JL, Merrick SH, Keith FM, Bronstein $\mathrm{MH}$, et al. Relationship of the proinflammatory cytokines to myocardial ischemia and dysfunction after uncomplicated coronary revascularization. J Thorac Cardiovasc Surg. 1994;108:626-35.

9. Finkel MS, Oddis CV, Jacob TD, Watkins SC, Hattler BG, Simmons RL. Negative inotropic effects of cytokines on the heart mediated by nitric oxide. Science. 1992;257:387-9.

10. de Waal M, Abrams J, Bennett B, Figdor CG, de Vries JE. Interleukin 10 (IL-10) inhibits cytokine synthesis by human monocytes: an autoregulatory role of IL-10 produced by monocytes. J Exp Med. 1991; 174:1209-20.

11. Wahl SM, McCartney-Francis N, Mergenhagen SE. Inflammatory and immunomodulatory roles of TGF-beta. Immunol Today. 1989;10:258-61.

12. Munoz C, Carlet J, Fitting C, Misset B, Bleriot JP, Cavaillon JM. Dysregulation of in vitro cytokine production by monocytes during sepsis. J Clin Invest. 1991;88:1747-1754.

13. Majetschak M, Flach R, Kreuzfelder E, Jennissen V, Heukamp T, Neudeck F, et al. The extent of traumatic damage determines a graded depression of the endotoxin responsiveness of peripheral blood mononuclear cells from patients with blunt injuries. Crit Care Med. 1999; 27:313-8.

14. Naldini A, Borrelli E, Cesari S, Giomarelli P, Toscano M. In vitro cytokine production and T-cell proliferation in patients undergoing cardiopulmonary by-pass. Cytokine. 1995;7:165-70.

15. Haskill S, Johnson C, Eierman D, Becker S, Warren K. Adherence induces selective mRNA expression of monocyte mediators and protooncogenes. J Immunol. 1988;140:1690-4.
16. Espevik T, Nissen-Meyer J. A highly sensitive cell line, WEHI 164 clone 13, for measuring cytotoxic factor/tumor necrosis factor from human monocytes. J Immunol Meth. 1986;95:99-105.

17. Saiki RK, Gelfand DH, Stoffel S, Scharf SJ, Higuchi R, Horn GT, et al. Primer-directed enzymatic amplification of DNA with a thermostable DNA polymerase. Science. 1988;239:487-91.

18. Wan S, Marchant A, DeSmet JM, Antoine M, Zhang H, Vachiery JL, et al. Human cytokine responses to cardiac transplantation and coronary artery bypass grafting. J Thorac Cardiovasc Surg. 1996;111:46977.

19. Hisatomi K, Isomura T, Kawara T, Yamashita M, Hirano A, Yoshida $\mathrm{H}$, et al. Changes in lymphocyte subsets, mitogen responsiveness, and interleukin-2 production after cardiac operations. J Thorac Cardiovasc Surg. 1989;98:580-91.

20. Cabie A, Fitting C, Farkas JC, Laurian C, Cormier JM, Carlet J, et al. Influence of surgery on in-vitro cytokine production by human monocytes. Cytokine. 1992;4:576-80.

21. Hattler BG, Zeevi A, Oddis CV, Finkel MS. Cytokine induction during cardiac surgery: analysis of TNF-alpha expression pre- and postcardiopulmonary bypass. J Card Surg. 1995;10:418-22.

22. Wan S, DeSmet JM, Barvais L, Goldstein M, Vincent JL, LeClerc JL. Myocardium is a major source of proinflammatory cytokines in patients undergoing cardiopulmonary bypass. $J$ Thorac Cardiovasc Surg. 1996;112:806-11.

23. Junger WG, Hoyt DB, Liu FC, Loomis WH, Coimbra R. Immunosuppression after endotoxin shock: the result of multiple anti-inflammatory factors. J Trauma. 1996;40:702-9.

24. Hart PH, Vitti GF, Burgess DR, Whitty GA, Piccoli DS, Hamilton JA. Potential antiinflammatory effects of interleukin 4: suppression of human monocyte tumor necrosis factor alpha, interleukin 1, and prostaglandin E2. Proc Natl Acad Sci U S A. 1989;86:3803-7.

25. Randow F, Syrbe U, Meisel C, Krausch D, Zuckermann H, Platzer C, et al. Mechanism of endotoxin desensitization: involvement of interleukin 10 and transforming growth factor beta. J Exp Med. 1995;181: 1887-92.

26. Wan S, LeClerc JL, Schmartz D, Barvais L, Huynh CH, Deviere J, et al. Hepatic release of interleukin-10 during cardiopulmonary bypass in steroid-pretreated patients. Am Heart J. 1997;133:335-9.

27. Attanasio M, Gori AM, Giusti B, Pepe G, Comeglio P, Brunelli T, et al. Cytokine gene expression in human LPS- and IFN $\gamma$-stimulated mononuclear cells is inhibited by heparin. Thromb Haemost. 1998;79: 959-62.

28. Royston D. Preventing the inflammatory response to open-heart surgery: the role of aprotinin and other protease inhibitors. Int J Cardiol. 1996;53 Suppl:S11-37.

29. Defraigne JO, Pincemail J, Larbuisson R, Blaffart F, Limet R. Cytokine release and neutrophil activation are not prevented by heparincoated circuits and aprotinin administration. Ann Thorac Surg. 2000; 69:1084-91.

30. Teoh KH, Bradley CA, Gauldie J, Burrows H. Steroid inhibition of cytokine-mediated vasodilation after warm heart surgery. Circulation. 1995;92(9 Suppl):II347-53.

31. Schade FU, Flach R, Flohé S, et al: Endotoxin tolerance. In: Brade H, Opal S, Vogel S, Morrison D, editors. Endotoxin in health and disease. New York: Marcel Dekker; 1999. p. 751-67.

32. Martinez-Pellus AE, Merino P, Bru M, Conejero R, Seller G, Munoz $\mathrm{C}$, et al. Can selective digestive decontamination avoid the endotoxemia and cytokine activation promoted by cardiopulmonary bypass? Crit Care Med. 1993;21:1684-91.

33. Flohé S, Börgermann J, Dominguez FE, Majetschak M, Lim L, Kreuzfelder E, et al. Influence of granulocyte-macrophage colonystimulating factor (GM-CSF) on whole blood endotoxin responsiveness following trauma, cardiopulmonary bypass, and severe sepsis. Shock. 1999;12:17-24. 